\title{
Fishing and Natural Mortality of Adult Largemouth Bass in a Tropical Reservoir
}

\author{
D. Scott Waters*1 and Richard L. Noble \\ Department of Zoology, North Carolina State University, \\ Campus Box 7617, Raleigh, North Carolina 27695-7617, USA \\ Joseph E. Hightower \\ U.S. Geological Survey, \\ North Carolina Cooperative Fish and Wildlife Research Unit, ${ }^{2}$ \\ Department of Zoology, North Carolina State University, \\ Raleigh, North Carolina 27695-7617, USA
}

\begin{abstract}
Largemouth bass Micropterus salmoides, an intensively studied sport fish of temperate North America, has been introduced into tropical regions, but with little evaluation of fishing or natural mortality rates. Previous research in Puerto Rico suggested that annual mortality rates are high, but whether the extended spawning season (nearly 6 months annually), high angler harvest, or a combination was the cause of the elevated mortality was unresolved. Using ultrasonic telemetry, we tracked 44 adult largemouth bass over an 18-month period to quantify patterns of natural, fishing, and total mortality. Using a general capture-recapture model, we estimated the annual instantaneous rates of fishing $(0.584, \mathrm{SE}=0.164)$ and natural mortality $(0.310, \mathrm{SE}=0.122)$. Natural mortality varied seasonally and generally increased during periods of spawning activity; however, fishing mortality was fairly consistent throughout the study. Given the relatively high fishing mortality rate, restrictions on harvest could probably be used to alter the age and size distribution of this population.
\end{abstract}

Largemouth bass Micropterus salmoides are native to the central and southeastern USA and have been intensively studied because of their importance as sport fish (Heidinger 1976). Introductions have extended the geographic range of this species. Largemouth bass were first successfully introduced into Puerto Rico in 1946 (Erdman 1984). The island contains 13 reservoirs and lagoons over 100 ha in size, which contain viable, reproducing largemouth bass populations. Numerous other small impoundments and farm ponds also support established populations.

Studies of largemouth bass in Puerto Rico indicate that annual mortality rates of adults are extremely high (78-90\%; Churchill et al. 1995), but causes for this mortality are not well understood. In Lucchetti Reservoir, length frequency histo-

\footnotetext{
* Corresponding author: scottw@wp.state.ks.us

${ }^{1}$ Present address: Kansas Department of Wildlife and Parks, Glen Elder Area Office, Rural Route 1, Post Office Box 162A, Glen Elder, Kansas 67446, USA.

2 The Unit is jointly supported by North Carolina State University, North Carolina Wildlife Resources Commission, U.S. Geological Survey, and Wildlife Management Institute.
}

Received November 5, 2003; accepted November 25, 2004 Published online May 5, 2005 grams reveal the adult stock to be composed mainly of two distinct size groups and few fish exceed $400 \mathrm{~mm}$ total length (Churchill et al. 1995). Based on microtagging studies, most adults were either age 1 or age 2 , few living beyond age 2 . One hypothesis to account for the short lifespan is high natural mortality due to the bioenergetic cost of an extended spawning season of nearly 6 months (Gran 1995; Waters and Noble 2004). An alternative hypothesis attributes mortality to high angler harvest. Few regulations have been implemented regarding size and creel limits on largemouth bass fishing, and a large portion of the fishing is consumptive. A telemetry study of largemouth bass in La Plata Reservoir, Puerto Rico, indicated that seven of nine fish died during a 1-year study (Lilyestrom and Churchill 1998). Four were confirmed captured by anglers, two disappeared (probably to unreported harvest), and one died naturally.

Creel surveys conducted in Lucchetti Reservoir indicate that although $89 \%$ of shore anglers did not target particular species in their effort, $81 \%$ of boat anglers identified largemouth bass as their preferred catch (Corujo-Flores 1991). The Lucchetti Field Station facilities are one of the best boating access areas in Puerto Rico, and the lake 
is highly popular among boating anglers. CorujoFlores (1991) estimated total fishing effort was nearly 20,000 h between August 1990 and July 1991, highest effort occurring between May and July $(6331 \mathrm{~h})$ and lowest between August and October $(2,947 \mathrm{~h})$.

Catch-and-release mortality may also contribute to the high overall mortality rate. Most Puerto Rican anglers do not have the sophisticated live wells and chemicals utilized by many anglers in the USA to facilitate live release during tournaments. A study in Lucchetti Reservoir estimated total mortality (initial and delayed) of tournament-caught fish at $42 \%$ (Neal and Lopez-Clayton 2001), which yields a conservative estimate of $6 \%$ annual mortality from tournament-released fish, based on the number of fish caught and released in a 23tournament season and the population estimate in Lucchetti Reservoir (Neal et al. 1999). Additional largemouth bass may succumb to hooking mortality during nontournament angling.

The objectives of our study were to investigate the rate, timing, and sources of adult largemouth bass mortality in Lucchetti Reservoir and to relate mortality to known spawning and angling events. This was accomplished by ultrasonically tracking a cohort of adult largemouth bass.

\section{Study Site}

Lucchetti Reservoir is a 108-ha impoundment located in the mountain region of southwestern Puerto Rico. The reservoir functions primarily as a storage impoundment providing water for irrigation to the arid Lajas Valley region. Similar to many reservoirs in Puerto Rico, Lucchetti Reservoir is characterized by steeply sloping shorelines and extreme variation in water level throughout the year (up to $17 \mathrm{~m}$ annually), causing dramatic changes in shoreline length, surface area, storage volume, and littoral habitat. Lucchetti Reservoir has been categorized as mesotrophic to eutrophic, based on nutrient concentrations, physical limnology, chlorophyll $a$, and phytoplankton biomass (Martínez 1979; Cham and Carvajal-Zamora 1981; Tilly 1983; PREQB 1992; Pérez Santos 1994). Lucchetti Reservoir supports both shoreline and boat-based sport fisheries for largemouth bass, redbreast tilapia Tilapia rendalli, Mozambique tilapia Tilapia mossambica, bluegill Lepomis macrochirus, channel catfish Ictalurus punctatus, and marbled bullhead Ameiurus nebulosus marmoratus.

\section{Methods}

In December 1997, we surgically implanted ultrasonic transmitters into the coelomic cavity of
50 adult largemouth bass collected by electrofishing. Ultrasonic transmitters were selected because they could be detected from deep water, whereas radio transmitter signals attenuate with depth (Winter 1983). We divided the lake into four areas, and an approximately equal number of fish were captured from each area. Because annulus formation does not occur on scales or otoliths at this latitude (Churchill et al. 1995), age was estimated using a length-frequency histogram from a recent population estimate. Transmitters were allocated equally between age- 1 and age- 2 fish and between males and females.

The Model CT-82-1 transmitters (Sonotronics, Inc.) used followed an on:off ratio of $2: 34 \mathrm{~h}$ to extend battery life, thereby allowing location of fish during both day and night. Transmitters (40 $\times 15 \mathrm{~mm}, 4 \mathrm{~g}$ ) operated at frequencies from 72 to $76 \mathrm{kHz}$, and each had a unique aural code. Because each ultrasonic tag transmitted for a 2 -h period, tagged fish were assigned to one of three consecutive 2 -h time slots, thereby facilitating location of about $1 / 3$ of the fish during a 2 -h assessment period. Each fish was randomly placed into one of three transmission time slots consisting of both day and night operation (0900 to 1100 hours and 2100 to 2300 hours, 1100 to 1300 hours and 2300 to 0100 hours, and 1300 to 1500 hours and 0100 to 0300 hours) so that two slots included 17 fish and one had 16. Based on the assumption that tagged fish return to normal behavior patterns within 1 month after tagging, tracking began in January 1998 and continued for 18 months. We used a DH2 directional hydrophone and USR-5W receiver (Sonotronics, Inc.) to locate transmitters manually by boat. Tracking was conducted once every 3-6 d during the spawning period (January to June) of each year but was reduced during nonspawning months (July to December) to once every 6-9 d. We attempted to search the entire reservoir during each 2-h time slot.

Once a fish's position was determined, its location was recorded on a detailed lake map, and a Garmin GPS 12 unit was used to identify UTM coordinates. Water depth, distance from shore, and habitat type were also recorded at the fish's location. In addition, water level and surface temperature were recorded during each sampling period.

Another project component using these same tagged fish was to investigate largemouth bass spawning dynamics, including timing, frequency, location, site fidelity, and movement rates (Waters and Noble 2004). That information was used in 
this study to determine whether spawning behavior was related to the timing of largemouth bass mortalities.

To obtain information on harvest, a message appeared on each transmitter requesting that anglers call the project laboratory when a tagged fish was harvested. Also, about half of the fishing tournaments were monitored for tagged fish, which were identified by the external observation of a smooth, white patch of skin around the incision area. To maintain normal harvest or release rates of tagged fish, no external tag was used, rewards were not offered for transmitters, and the project was not publicized.

Following the approach used by Hightower et al. (2001), we assumed that a transmitter that ceased movement represented a natural mortality, although catch-and-release delayed mortality was also a possible cause, especially following a tournament (Neal and Lopez-Clayton 2001). Tags that were undetected on multiple search occasions were assumed to have disappeared due to one of four possible causes: (1) unreported harvest mortality; (2) transmitter failure; (3) migration of fish over the dam or upriver during high-water periods; or (4) transport out of the lake by predators. Radiotelemetry results suggest that avian predation could account for a small fraction of lost tags (Waters 1999), but the primary mechanism was assumed to be unreported harvest mortality.

Fishing and natural mortality rates were estimated using the general capture-recapture model developed by Pollock et al. (1995) and modified by Hightower et al. (2001). The model accounted for not all fish being located during each tracking session by including relocation probability parameters and modeling the number of relocated fish rather than the total number at risk. Fishing mortality was estimated indirectly from the decreasing number of live fish relocated over time, whereas relocations of dead fish yielded a direct estimate of natural mortality. Information about relocation probabilities was obtained from fish missed during a tracking session but found on a later date.

Similar to Burnham et al. (1987) and Hightower et al. (2001), only the first relocation of a fish in release $R_{i}$ was considered. Fish first relocated alive during time $j$ became part of the tagged population newly released at time $j+1$. Modeling the expected number of fish from the $i$ th release that were first relocated at search $i+1$ or $i+2$ yielded the parameter estimates. The product of the number released $\left(R_{i}\right)$, the survival rate from time $i$ to $i+$ $1\left[S_{i}=\exp \left(-F_{i}-M_{i}\right)\right]$, and the individual relo- cation probability during search $i+1\left(p_{i+1}\right)$ yielded the expected number from release $R_{i}$ first relocated alive at time $i+1$ as

$$
R_{i}\left[\exp \left(-F_{i}-M_{i}\right)\right] p_{i+1},
$$

where $F_{i}$ is the instantaneous rate of fishing mortality and $M_{i}$ is the instantaneous rate of natural mortality at time $i$. The expected number of live fish first relocated at time $i+2$ following release $R_{i}$ would be

$$
\begin{aligned}
& R_{i}\left[\exp \left(-F_{i}-M_{i}\right)\right]\left(1-p_{i+1}\right) \\
& \quad \times\left[\exp \left(-F_{i+1}-M_{i+1}\right)\right] p_{i+2} .
\end{aligned}
$$

The expected number of natural deaths from release $R_{i}$ first relocated at time $i+1$ would be

$$
R_{i} \cdot M_{i} \cdot \frac{1-\exp \left(-F_{i}-M_{i}\right)}{\left(F_{i}+M_{i}\right)} \cdot p_{i+1} .
$$

The expected number of natural deaths from release $R_{i}$ first relocated at time $i+2$ would be

$$
\begin{gathered}
R_{i}\left[\exp \left(-F_{i}-M_{i}\right)\right]\left(1-p_{i+1}\right) \cdot M_{i+1} \\
\quad \times \frac{1-\exp \left(-F_{i+1}-M_{i+1}\right)}{\left(F_{i+1}+M_{i+1}\right)} \cdot p_{i+2} .
\end{gathered}
$$

Expressions were only needed for times $i+1$ and $i+2$ because all fish in this study were relocated on the first or second tracking period following release. Annual mortality estimates were obtained by summing $F$ and $M$ across periods and adjusting to 1 year.

We estimated model parameters by 2 -week intervals using program SURVIV (White 1983). This typically involved grouping two to four search occasions into each interval, which increased the relocation probabilities. If a fish was relocated alive at least once during the 2-week interval, it was classified as alive for that period. If a fish was relocated dead during that interval, it was classified as a natural death. Because no fish were missed in search occasions immediately before the discovery of a natural mortality, time of death could be precisely estimated.

We assumed the following:

(1) Each tagged fish alive and in Lucchetti Reservoir at time $i$ had an equal probability of surviving to the next tracking event.

(2) All tagged fish in Lucchetti Reservoir at time $i$ (alive or dead) had an equal probability $p_{i}$ of being relocated during the $i$ th tracking event. 
TABLE 1.-Biological data and tracking information for ultrasonically tagged largemouth bass.

\begin{tabular}{|c|c|c|c|c|c|c|c|}
\hline $\begin{array}{c}\text { Fish } \\
\text { number }\end{array}$ & $\operatorname{Sex}^{\mathrm{a}}$ & Age (years) & $\begin{array}{l}\text { Total length } \\
\quad(\mathrm{mm})\end{array}$ & $\begin{array}{l}\text { Weight } \\
\text { (g) }\end{array}$ & Fate $^{b}$ & Last detected & $\begin{array}{l}\text { Number of } \\
\text { relocations }\end{array}$ \\
\hline 1 & M & 1 & 315 & 420 & Sacrificed & 20 Feb 1999 & 71 \\
\hline 3 & M & 1 & 278 & 256 & Harvested & 1 Feb 1998 & 5 \\
\hline 4 & M & 2 & 340 & 482 & Harvested & 31 Jul 1998 & 47 \\
\hline 5 & M & 2 & 388 & 787 & Harvested* & $11 \mathrm{Feb} 1999$ & 67 \\
\hline 6 & M & 2 & 345 & 425 & Died naturally & 19 Aug 1998 & 44 \\
\hline 7 & $\mathrm{~F}$ & 1 & 303 & 329 & Alive & 27 May 1999 & 87 \\
\hline 8 & $\mathrm{~F}$ & 1 & 320 & 436 & Hurricane & 17 Sep 1998 & 48 \\
\hline 9 & $\mathrm{~F}$ & 1 & 270 & 238 & Hurricane & 17 Sep 1998 & 48 \\
\hline 11 & F & 2 & 331 & 442 & Sacrificed & 11 Jun 1999 & 89 \\
\hline 12 & $\mathrm{~F}$ & 2 & 373 & 730 & Harvested & 12 Мау 1999 & 71 \\
\hline 13 & M & 1 & 321 & 404 & Harvested* & 20 Jan 1998 & 3 \\
\hline 14 & M & 1 & 325 & 478 & Harvested* & 25 Jun 1998 & 40 \\
\hline 15 & M & 1 & 309 & 345 & Died naturally & 19 Mar 1999 & 69 \\
\hline 17 & M & 2 & 330 & 462 & Sacrificed & 21 Apr 1999 & 77 \\
\hline 18 & M & 2 & 330 & 462 & Harvested & 16 Jul 1998 & 38 \\
\hline 19 & $\mathrm{~F}$ & 1 & 295 & 359 & Harvested* & 12 Aug 1998 & 50 \\
\hline 20 & $\mathrm{~F}$ & 1 & 309 & 357 & Harvested* & 19 Nov 1998 & 58 \\
\hline 21 & F & 1 & 327 & 358 & Harvested & 16 Jul 1998 & 43 \\
\hline 22 & $\mathrm{~F}$ & 2 & 375 & 711 & Harvested* & 23 Jan 1998 & 4 \\
\hline 23 & $\mathrm{~F}$ & 2 & 368 & 555 & Harvested & 29 Jan 1998 & 1 \\
\hline 24 & $\mathrm{~F}$ & 2 & 345 & 482 & Died naturally & 28 Feb 1998 & 11 \\
\hline 25 & M & 1 & 305 & 362 & Died naturally & 1 Feb 1998 & 6 \\
\hline 26 & M & 1 & 268 & 245 & Harvested* & 18 Mar 1998 & 15 \\
\hline 27 & M & 1 & 322 & 470 & Alive & 11 Jun 1999 & 72 \\
\hline 28 & M & 2 & 362 & 654 & Harvested* & 3 Apr 1999 & 79 \\
\hline 30 & M & 2 & 365 & 565 & Hurricane & 17 Sep 1998 & 48 \\
\hline 31 & $\mathrm{~F}$ & 1 & 328 & 497 & Harvested* & 5 Apr 1998 & 20 \\
\hline 32 & $\mathrm{~F}$ & 1 & 271 & 248 & Died naturally & 28 Feb 1998 & 10 \\
\hline 33 & $\mathrm{~F}$ & 1 & 308 & 385 & Tag failure & 12 Aug 1998 & 41 \\
\hline 35 & $\mathrm{~F}$ & 2 & 378 & 587 & Hurricane & 17 Sep 1998 & 54 \\
\hline 36 & M & 2 & 378 & 776 & Hurricane & 17 Sep 1998 & 48 \\
\hline 37 & M & 1 & 311 & 386 & Harvested* & 14 Jan 1998 & 1 \\
\hline 38 & M & 1 & 282 & 314 & Harvested* & 2 May 1998 & 27 \\
\hline 39 & M & 1 & 314 & 383 & Hurricane & 17 Sep 1998 & 45 \\
\hline 40 & $\mathrm{~F}$ & 2 & 361 & 606 & Died naturally & 26 Feb 1999 & 69 \\
\hline 41 & M & 2 & 342 & 555 & Died naturally & 9 Mar 1998 & 13 \\
\hline 42 & M & 2 & 338 & 505 & Died naturally & 19 Aug 1998 & 44 \\
\hline 44 & $\mathrm{~F}$ & 1 & 314 & 430 & Died naturally & 6 May 1999 & 77 \\
\hline 45 & $\mathrm{~F}$ & 1 & 319 & 407 & Died naturally & 10 Jun 1998 & 35 \\
\hline 46 & M & 2 & 355 & 576 & Died naturally & 12 May 1999 & 83 \\
\hline 47 & $\mathrm{~F}$ & 2 & 361 & 640 & Alive & 11 Jun 1999 & 86 \\
\hline 48 & M & 2 & 363 & 658 & Harvested & 26 Feb 1999 & 59 \\
\hline 49 & $\mathrm{~F}$ & 1 & 325 & 444 & Tag failure & 19 Mar 1999 & 58 \\
\hline 50 & F & 2 & 387 & 752 & Alive & 11 Jun 1999 & 64 \\
\hline
\end{tabular}

${ }^{\mathrm{a}} \mathrm{F}=$ female, $\mathrm{M}=$ male.

b Fish classified as "harvested" were caught and reported by anglers; asterisks indicate that the fish were assumed to have been harvested but that this was not actually reported.

(3) All fish behaved independently with respect to survival and relocation probabilities.

(4) Any fish repeatedly located at the same location was classified as a natural mortality.

(5) Fish leaving Lucchetti Reservoir were assumed to have been harvested or migrated over the dam or up a river.

(6) The probability of a transmitter failing or being shed was negligible.

(7) Fish handling and transmitter implantation had no effect on fish survival or behavior, thus allowing application of the results to the entire population.

\section{Results}

The 50 adult largemouth bass tagged in December 1997 ranged from 268 to $399 \mathrm{~mm}$ total length (mean $=331 \mathrm{~mm}, \mathrm{SD}=32$ ) and 238-829 $\mathrm{g}$ (mean $=476 \mathrm{~g}, \mathrm{SD}=146$; Table 1 ). Two fish were never relocated during the study, three died before the first search occasion and were assumed to have experienced surgery-related mortality, and one 
was harvested before tracking began. Data for these six fish were excluded from analyses. The remaining 44 fish were tracked for periods ranging from 1 to $536 \mathrm{~d}($ mean $=254 \mathrm{~d}, \mathrm{SD}=171)$ from January 1998 to June 1999. We recorded 2,025 ultrasonic locations during 92 tracking events (Table 1). Not all tagged fish were located on all search occasions because of time limitations of the 2-h tracking frame, temporary loss of signal, or weather-shortened tracking sessions.

Seven telemetered fish were recaptured in January-March 1998 during electrofishing associated with other project objectives. Surgical incisions appeared to heal well, only slight scarring and a smooth, white patch of skin being noted around the incision area. All fish appeared healthy and in good condition and had gained weight after implantation. These fish were released at their capture sites with no apparent adverse immediate or delayed effects from the electrofishing. Three fish were recaptured and sacrificed near completion of the study to observe the placement of the transmitter within the coelomic cavity and determine if any negative effects from the tagging procedure were evident. Each fish appeared healthy when recaptured, and the transmitter had become encapsulated in a pocket of fatty tissue that was separate from the internal organs.

Of the 44 tagged fish, only 4 were known to have survived the entire 18-month study period (Table 1), 7 (16\%) were reported captured and harvested by anglers (their tags were returned), and $11(25 \%)$ were assigned to in-lake natural or catchand-release mortality because the tags ceased movement. Ten of these 11 transmitters were recovered as water levels receded, thus confirming their fate. Seventeen fish (39\%) were lost to unknown causes, of which 11 were assumed to have been harvested by anglers but not reported. The other 6 fish were absent from the lake on 29 September, the first tracking event following Hurricane Georges (21 September), although they had been present only $3 \mathrm{~d}$ before the hurricane. They apparently left the lake either by moving upriver or over the dam during high flows due to torrential rains. These 6 fish were censored from the analysis after their final location so as not to bias estimates of $F$. Of the 9 remaining fish, 3 were sacrificed and were censored from the study, and 2 had transmitter failures characterized by inconsistent signals preceding total loss of signal. Tag failure of fish 33 was verified by recapture of the fish on 1 September 1999. The transmitter for fish 49 was assumed to have failed because its signal ceased to be detected between late November 1998 and early March 1999, was located during four search occasions in mid to late March 1999, but was not detected thereafter. To verify that no other transmitter failures occurred, we continued to monitor all tags that had been classified as natural mortalities and transmitters collected from angler returns and sacrificed fish. No transmitter failures occurred in these 21 tags before tracking ceased on 11 June 1999, indicating little likelihood of transmitter failure in fish classified as unreported angling mortalities or lost to the hurricane.

The full model with separate parameters for each biweekly period consisted of 37 relocation probabilities $(p), 37 F$ parameters, and $8 M$ parameters. $M$ was fixed at 0 for all periods when no natural mortality was observed. This model (varying $F$, $M, p$ ) provided a better fit for the data, based on a likelihood ratio test $\left(\chi^{2}=113.3\right.$, df $=33, P<$ 0.0001] or Akaike's Information Criterion (138.8) when compared with a reduced model that assumed constant $F, M$, and $p(\mathrm{AIC}=186.1)$.

During the final two periods, two purported natural mortalities and one confirmed fishing mortality occurred. Combined with several fish not being relocated, this resulted in extremely high variances, especially compared to the previous 35 search occasions. For that reason, and the inconsistency of determining whether a fish missed during the last two search occasions was harvested or simply not relocated, all estimates of annual rates were based on the first 35 periods, but data for all 37 periods are presented.

Mean (among 35 periods) annual instantaneous rates of fishing and natural mortality were 0.584 $(\mathrm{SE}=0.164)$ and $0.313(\mathrm{SE}=0.122)$, yielding an annual rate of total mortality $(Z)$ of 0.894 and an annual survival rate of 0.409 . Excluding period 26 , when no searches were conducted, relocation probability averaged 0.96 , varing slightly from 0.92 to 1.00 (Figure 1). Relocation probability was typically 1.00 , except during the latter half of the first year when only one or two searches were made during an interval compared with three or four in previous periods.

Fishing mortalities were estimated to have occurred throughout the year but natural mortality varied seasonally (Figure 1). Between September 1998 and February 1999, $F$ was very low, in part, presumably because the lake was closed between mid-September and early December due to the hurricane. Natural mortalities occurred between 11 February 1998 and 11 March 1998, 17 June 1998 and 26 August 1998, and 10 March 1999 and 24 

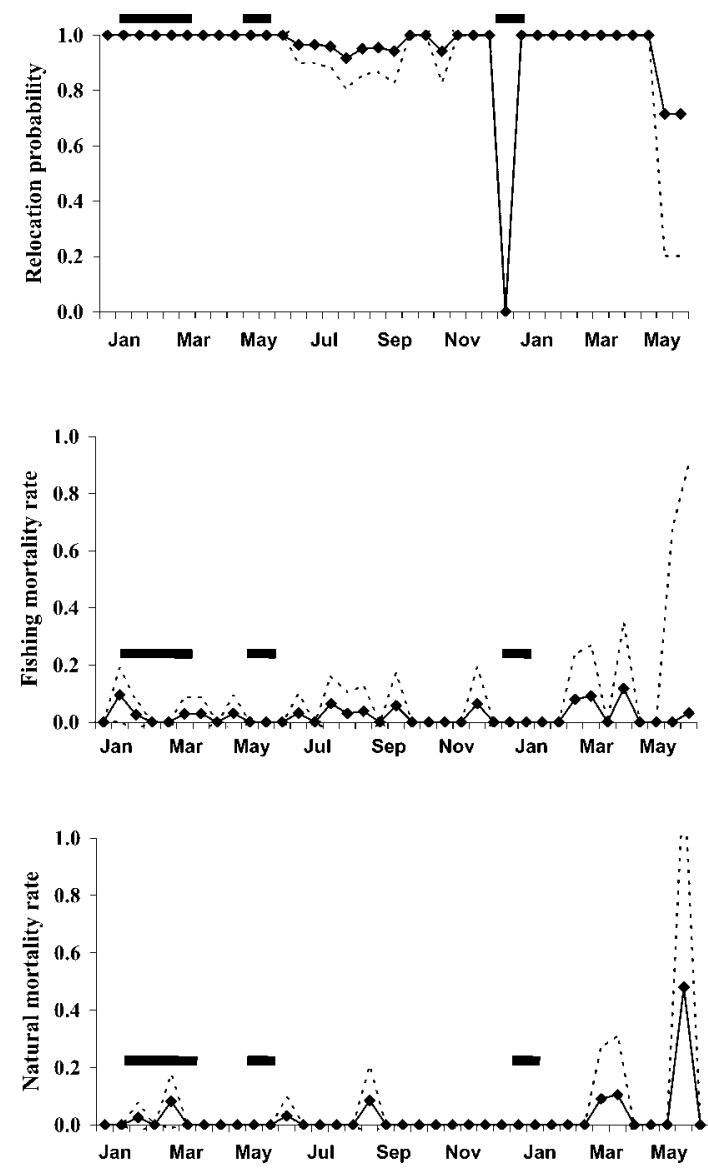

FIGURE 1.-Estimated relocation probabilities for each search occasion (upper panel) and instantaneous biweekly fishing (center panel), and natural mortality rates (lower panel), as related to sonically tagged largemouth bass in Lucchetti Reservoir Puerto Rico, 19981999. Solid lines are estimates; dashed lines are $95 \%$ confidence intervals. Dark bars above individual points represent periods of spawning activity (Waters and Noble 2004).

March 1999. The first set of dates correspond to the estimated largemouth bass spawning season in the reservoir, and the second and third are postspawning periods (Waters and Noble 2004). Nearing completion of the study, $M$ was also high because 2 of only 12 remaining fish suffered natural mortality.

\section{Discussion}

Prior studies based on recaptures of microtagged fish had shown that mortality rates of largemouth bass in Lucchetti Reservoir are extremely high (Churchill et al. 1995; Neal et al. 1999). Results of our telemetry study confirmed the high total mortality rate and allowed direct estimates of timing and sources of mortality.

Our estimate of $M(0.310)$ is slightly lower than typical estimates from other systems. Beamesderfer and North (1995) compiled estimates of $M$ from 40 largemouth bass populations in North America and reported a range of $0.02-1.22$, an overall median of 0.42 , and a mean of 0.46 . They also reported that $M$ increased with decreasing latitude and increasing air temperature and degree-days above $10^{\circ} \mathrm{C}$. Based on these patterns, natural mortality in Lucchetti Reservoir is lower than would be expected, considering its location and yeararound elevated temperature. Furthermore, our estimate of $M$ is a maximum, which could potentially be lower if mortalities could be differentiated between natural and catch-and-release delayed mortality.

Natural mortality was highly seasonal, most deaths occurring during and immediately following the spawning season (Figure 1). Previous research in Lucchetti Reservoir indicated that spawning occurred over several months (Gran 1995). A prolonged spawning season may be bioenergetically expensive and could increase natural mortality. Catch-and-release mortality may also contribute substantially to our estimated natural (nonharvest) mortality rate. Lucchetti Reservoir is host to approximately two fishing tournaments each month. These tournaments usually occur on weekends over 2 d. A tournament mortality study revealed that approximately $66 \%$ of released tournament-caught fish suffer mortality within $4 \mathrm{~d}$ (Neal and LopezClayton 2001). This estimate can be extrapolated to an annual estimate of $6 \%$ mortality in the reservoir. Live wells are not often used, and fish are sometimes kept out of water for up to 10 min during weigh-in. We observed that many of the released fish were nearly dead when returned to the reservoir. Furthermore, elevated water temperatures found in the tropics lead to additional stress and risk of death due to the correlation between water temperature and both prerelease and total mortality (Neal and Lopez-Clayton 2001; Schramm et al. 1987; Meals and Miranda 1994). No tagged fish were observed during the tournaments that were monitored, but on the first search occasion following an unmonitored tournament, one tagged fish was relocated dead approximately $50 \mathrm{~m}$ from the weigh-in site. This fish, which was classified as a natural mortality, was probably caught during the tournament, released, and died almost immediately. Thus, we believe that catch-and-release mortality should continue to be monitored closely. 
We estimated annual exploitation rate for largemouth bass in Lucchetti Reservoir was 0.38, which is generally similar to results for U.S. waters in the 1980s but double that of recent studies. For example, during 1988-1989 Pitlo and Bonneau (1992) studied five largemouth bass populations in Iowa and found that annual exploitation ranged from 0.15 to 0.53 (mean 0.35). More recent estimates have typically been 0.20 or lower (e.g., O'Bara et al. 2001; Renfro et al. 1999; DiCenzo and Garren 2003). Largemouth bass angling in Lucchetti Reservoir is largely consumptive (i.e., little catch and release). There is no enforced size limit and a liberal creel limit of 12 fish/d. Furthermore, Lucchetti Reservoir has the best access for anglers on the island, which contributes to the potential for overharvest of largemouth bass.

Water level may be indirectly related to fishing mortality because of its effects on fish behavior and location and angler habits. Fishing mortality was high and fairly constant throughout the first 7 months of the study, but was typically zero between mid-August 1998 and mid-February 1999. This period of low fishing mortality could be partly attributed to the 2-month period immediately following Hurricane Georges, when public access to the lake was closed. Another likely explanation for decreased fishing mortality is that lake levels decreased substantially after hurricane flooding ended. Largemouth bass are consistently found offshore and become more mobile under low-water conditions (Waters and Noble 2004). This would cause the fish to be less susceptible to harvest because anglers typically concentrate their efforts on the shoreline and littoral zone and ignore the pelagic area. Low water levels may also act as a deterrent to anglers and cause them to view the lake as unappealing and unproductive, thereby decreasing fishing pressure.

Churchill et al. (1995) suggested that the short lifespan (most $<3$ years) of largemouth bass in Lucchetti Reservoir would allow for high fishing pressure to take advantage of the fast-growing, quick-dying population. They also stated that the short life span would preclude a trophy fishery. Those recommendations were based on the assumption that the high total mortality was due to correspondingly high natural mortality, rather than harvest. Our telemetry-based approach allowed us to estimate the relative impacts of fishing versus natural mortality, and the results suggest that age and size distributions of largemouth bass in Lucchetti Reservoir could be altered by implementating more restrictive harvest regulations. Ozen and
Noble (2002) evaluated minimum size limits of 279, 305, and $330 \mathrm{~mm}$ total length in Lucchetti Reservoir and reported that a $305-\mathrm{mm}$ limit resulted in the highest yield, when $M$ is greater than 0.40 , but a $330-\mathrm{mm}$ minimum size limit maximized yield when $M$ was near 0.30 and $F$ was greater than 0.40 . These yield models are based on the assumption that natural and fishing mortality rates are additive rather than compensatory. This assumption is supported by a review of published estimates of exploitation and total mortality rates for largemouth bass (Allen et al. 1998).

There is evidence from other systems that tropical largemouth bass populations can be managed for older and larger fish. For example, Mexico is well known for its reservoirs that draw U.S. anglers seeking trophy-sized largemouth bass. Other reservoirs in Puerto Rico consistently produce largemouth bass greater than $3,000 \mathrm{~g}$ and $500 \mathrm{~mm}$ (Neal et al. 1999). Although each reservoir behaves differently with respect to the biotic community, responses to environmental cues, and effectiveness of largemouth bass harvest regulations, there appears to be potential for restructuring the Lucchetti Reservoir population to produce older and larger fish, if deemed appropriate by fishery managers and users of the resource.

\section{Acknowledgments}

We thank Wes Neal, Dan Ashe, Grisel Rodriguez, Felix Del Toro, Randy Jackson, and Brad Taylor for field assistance. Special thanks to Ken Pollock for his invaluable contribution with model development and data analysis and Craig Lilyestrom for his assistance throughout the project. We also thank the Lucchetti Reservoir Field Management Station personnel for their cooperation and assistance and for allowing us to use their equipment throughout the study. Tom Kwak, Jim Rice, Mike McInerny, and three anonymous reviewers provided comments that greatly improved the manuscript. This research was funded by Federal Aid in Sport Fish Restoration Project F-41-2 conducted by North Carolina State University and the Puerto Rico Department of Natural and Environmental Resources through the North Carolina Agricultural Research Service.

\section{References}

Allen, M. S., L. E. Miranda, and R. E. Brock. 1998. Implications of compensatory and additive mortality to the management of selected sport fish populations. Lakes and Reservoirs Research and Management 3:67-79. 
Beamesderfer, R. C., and J. A. North. 1995. Growth, natural mortality, and predicted response to fishing for largemouth bass and smallmouth bass populations in North America. North American Journal of Fisheries Management 15:688-704.

Burnham, K. P., D. R. Anderson, G. C. White, C. Brownie, and K. H. Pollock. 1987. Design and analysis methods for fish survival experiments based on releasecapture data. American Fisheries Society, Monograph 5, Bethesda, Maryland.

Cham, C. M., and J. Carvajal-Zamora. 1981. A study of phytoplankton in sixteen reservoirs (artificial lakes) in Puerto Rico. Pages 86-116 in Proceedings of the Simposio de los Recursos Naturales. Puerto Rico Department of Natural and Environmental Resources, San Juan.

Churchill, T. N., R. L. Noble, J. E. Gran, and A. R. Alicea. 1995. Largemouth bass recruitment in Lucchetti Reservoir. Puerto Rico Department of Natural and Environmental Resources. Federal Aid in Sport Fish Restoration, Project F-16, Study 2, Final Report, San Juan.

Corujo-Flores, I. N. 1991. Reservoir sport fish survey. Puerto Rico Department of Natural and Environmental Resources, Federal Aid in Sport Fish Restoration, Project F-16, Study 1, Final Report, San Juan.

DiCenzo, V. J., and D. A. Garren. 2003. Trophy largemouth bass abundance and harvest in a central Virginia impoundment: implications for restrictive slot limits. Proceedings of the Annual Conference Southeastern Association Fish and Wildlife Agencies 55(2001):194-207.

Erdman, D. S. 1984. Exotic fishes in Puerto Rico. Pages 162-176 in W. R. Courtenay and J. R. Stauffer Jr., editors. Distribution, biology, and management of exotic fishes. Johns Hopkins University Press, Baltimore, Maryland.

Gran, J. E. 1995. Gonad development and spawning of largemouth bass in a tropical reservoir. Master's thesis. North Carolina State University, Raleigh.

Heidinger, R. C. 1976. Synopsis of biological data on the largemouth bass, Micropterus salmoides (Lacepede) 1802. FAO (Food and Agriculture Organization of the United Nations) Fisheries Synopsis 115.

Hightower, J. E., J. R. Jackson, and K. H. Pollock. 2001. Use of telemetry methods to estimate natural and fishing mortality of striped bass in Lake Gaston, North Carolina. Transactions of the American Fisheries Society 130:557-567.

Lilyestrom, C. G., and T. N. Churchill. 1998. Diet and movement of largemouth bass and butterfly peacocks in La Plata Reservoir, Puerto Rico. Proceedings of the Annual Conference Southeastern Association Fish and Wildlife Agencies 50(1996): 192-200.

Martínez, R. F. 1979. Estudio comparativo de la limnología de los embalses mayores de Puerto Rico. [Comparative study of the limnology of the major reservoirs of Puerto Rico.] Master's thesis. University of Puerto Rico, Rio Piedras.
Meals, K. O., and L. E. Miranda. 1994. Size-related mortality of tournament-caught largemouth bass. North American Journal of Fisheries Management 14:460-463.

Neal, J. W., R. L. Noble, C. G. Lilyestrom, T. N. Churchill, A. R. Alicea, D. E. Ashe, F. M. Holliman, and D. S. Waters. 1999. Freshwater sport fish community investigations and management. Puerto Rico Department of Natural and Environmental Resources, Federal Aid in Sport Fish Restoration, Project F-41-2, Final Report, San Juan.

Neal, J. W., and D. Lopez-Clayton. 2001. Mortality of largemouth bass during catch and release tournaments in a Puerto Rico reservoir. North American Journal of Fisheries Management 21:834-842.

O'Bara, C. J., C. E. McCracken, and D. C. Peterson. 2001. Angler exploitation and angling mortality of largemouth bass and spotted bass at Norris Reservoir, Tennessee. Proceedings of the Annual Conference Southeastern Association Fish and Wildlife Agencies 53(1999):150-161.

Ozen, O., and R. L. Noble. 2002. Yield-per-recruit simulation analyses for a largemouth bass population in Lucchetti Reservoir, Puerto Rico. Proceedings of the Annual Conference of the Southeastern Association Fish and Wildlife Agencies 54(2000):59-69.

Pérez Santos, I. 1994. Monitoring of recreational fishes and their habitat. Puerto Rico Department of Natural and Environmental Resources, Federal Aid in Sportfish Restoration, Project F-5, Final Report, San Juan.

Pitlo, J., and D. Bonneau. 1992. An evaluation of largemouth bass populations in the upper Mississippi River. Iowa Department of Natural Resources, Mississippi River Investigations, Federal Aid to Fish Restoration, Project F-109-R, Completion Report, Des Moines.

Pollock, K. H., C. M. Bunck, S. R. Winterstein, and C. L. Chen. 1995. A capture-recapture survival analysis model for radio-tagged animals. Journal of Applied Statistics 22:661-672.

PREQB (Puerto Rico Environmental Quality Board). 1992. Goals and progress of statewide water quality management planning: Puerto Rico 1990-1991. PREQB, San Juan.

Renfro, D. J., W. F. Porak, and S. Crawford. 1999. Angler exploitation of largemouth bass determined using variable reward tags in 2 central Florida lakes. Proceedings of the Annual Conference Southeastern Association Fish and Wildlife Agencies 51(1997): 175-183.

Schramm, H. L., Jr., P. J. Haydt, and K. M. Portier. 1987. Evaluation of prerelease, postrelease, and total mortality of largemouth bass caught during tournaments in two Florida lakes. North American Journal of Fisheries Management 7:394-402.

Tilly, L. J. 1983. A review of the trophic state classification of Puerto Rican lakes. Pages 49-56 in Proceedings of the Simposio de los Recursos Naturales de Puerto Rico. Puerto Rico Department of Natural Resources, San Juan.

Waters, D. S. 1999. Spawning season and mortality of 
adult largemouth bass (Micropterus salmoides) in a tropical reservoir. Master's thesis. North Carolina State University, Raleigh.

Waters, D. S., and R. L. Noble. 2004. Spawning season and nest fidelity of largemouth bass in a tropical reservoir. North American Journal of Fisheries Management 24:1240-1251.
White, G. C. 1983. Numerical estimation of survival rates from band recovery and biotelemetry data. Journal of Wildlife Management 47:716-728.

Winter, J. D. 1983. Underwater biotelemetry. Pages 371-395 in L. A. Nielsen and D. L. Johnson, editors. Fisheries techniques. American Fisheries Society, Bethesda, Maryland. 